Case Report

\title{
Radiation Therapy-Induced Cardiovascular Disease Treated by a Percutaneous Approach
}

\author{
Luigi Fiocca, ${ }^{1}$ Micol Coccato, ${ }^{1}$ Vasile Sirbu, ${ }^{1}$ Angelina Vassileva, ${ }^{1}$ \\ Giulio Guagliumi, ${ }^{1}$ Giuseppe Musumeci, ${ }^{1}$ Amedeo Terzi, ${ }^{1}$ Gianluca Canu, ${ }^{1}$ \\ Elisa Cerchierini, ${ }^{2}$ Diego Cugola, ${ }^{1}$ and Orazio Valsecchi ${ }^{1}$ \\ ${ }^{1}$ Cardiovascular Department, Papa Giovanni XXIII Hospital, 24127 Bergamo, Italy \\ ${ }^{2}$ Anesthesia and Intensive Care Department, Papa Giovanni XXIII Hospital, 24127 Bergamo, Italy
}

Correspondence should be addressed to Luigi Fiocca; luigifiocca@gmail.com

Received 18 January 2015; Revised 13 April 2015; Accepted 16 April 2015

Academic Editor: Kenei Shimada

Copyright (c) 2015 Luigi Fiocca et al. This is an open access article distributed under the Creative Commons Attribution License, which permits unrestricted use, distribution, and reproduction in any medium, provided the original work is properly cited.

We report the case of a 51-year-old woman, treated with radiotherapy at the age of two years, for a pulmonary sarcoma. Subsequently she developed severe aortic stenosis and bilateral ostial coronary artery disease, symptomatic for dyspnea (NYHA III functional class). Due to the prohibitive surgical risk, she underwent successful stenting in the right coronary artery and left main ostia with drug eluting stents and, afterwards, transcatheter aortic valve replacement with transfemoral implantation of a $23 \mathrm{~mm}$ Edwards SAPIEN XT valve. The percutaneous treatment was successful without complications and the patient is in NYHA II functional class at 2 years' follow-up, fully carrying out normal daily activities.

\section{Introduction}

Cardiovascular diseases in patients who undergo thoracic radiotherapy represent a significant reason for long-term mortality. Vascular disease after radiotherapy usually occurs through an accelerated development of age related atherosclerosis, often involving coronary ostia, resulting in an increased risk of myocardial infarction or sudden cardiac death [1]. Early fibrosis, involving cardiac valves, is common after radiotherapy, with important prognostic consequences [2-4].

Surgery management of these patients is troublesome, due to anatomical sequelae of radiation exposure, with adherence and pulmonary fibrosis that increase the surgical risk.

Percutaneous treatment of coronary and structural disease is nowadays widely applied, representing a valid option for high surgical risk patients.

Transcatheter aortic valve implantation (TAVI) is increasingly popular as an alternative for symptomatic patients affected by severe aortic stenosis that are at high risk for surgery [5-7].

\section{Case Report}

A 51-year-old woman with pulmonary fibrosarcoma diagnosed at age 2, treated with repeated cycles of radiotherapy, presented with exertional dyspnea.

She had late sequelae of radiotherapy including mediastinal and left pulmonary fibrosis, with severe restrictive lung disease (Figure 1). She underwent a cardiologic evaluation for worsening dyspnea, which revealed a markedly impaired functional capacity (NYHA III functional class). Transthoracic and transesophageal echocardiogram revealed mildly impaired left ventricular function (ejection fraction $45 \%$ ), severe aortic stenosis (mean gradient $40 \mathrm{mmHg}$, indexed valve area $0.5 \mathrm{~cm}^{2} / \mathrm{m}^{2}$ ), and moderate aortic and mitral regurgitation. An angio-CT scan showed thickening and calcification of the aortic valve and a porcelain aorta, supporting the diagnosis of radiation-induced cardiovascular disease (Figure 1).

Afterwards, she was admitted to our cardiology department for an invasive evaluation. Coronary angiography showed focal critical ostial left main (LM) stenosis (with 


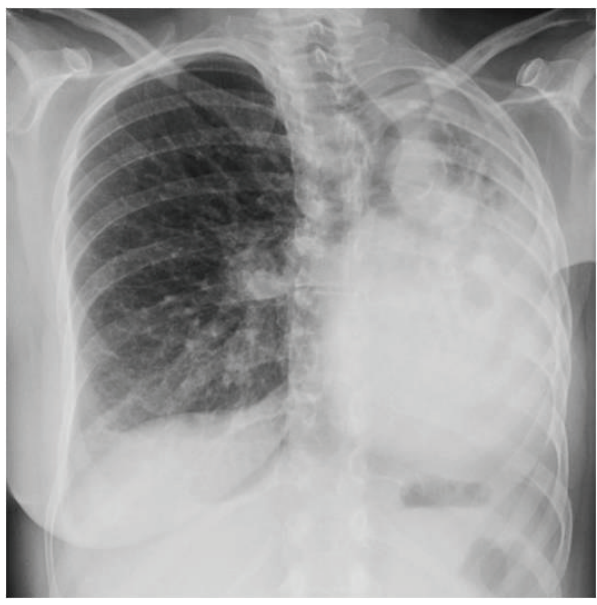

(a)

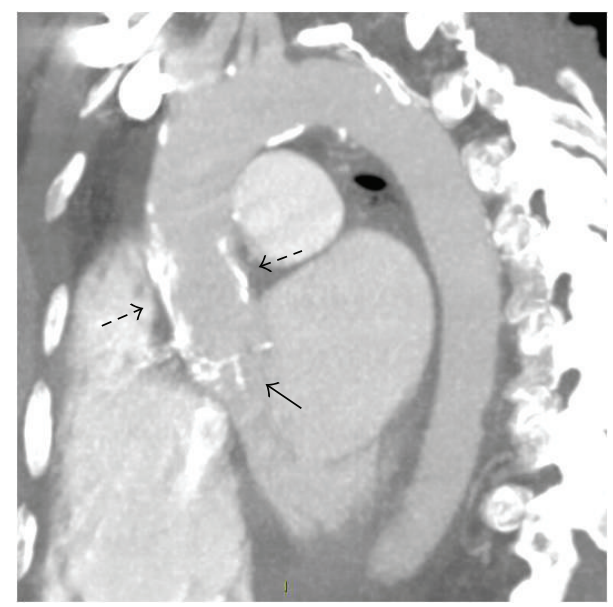

(b)

FIGURE 1: (a) Chest X-ray demonstrating left fibrothorax with ipsilateral mediastinum and trachea displacement. (b) CT scan demonstrating thickening and calcification of the aortic valvular leaflets (arrow) and diffuse calcification of the ascending aorta (dashed arrows).

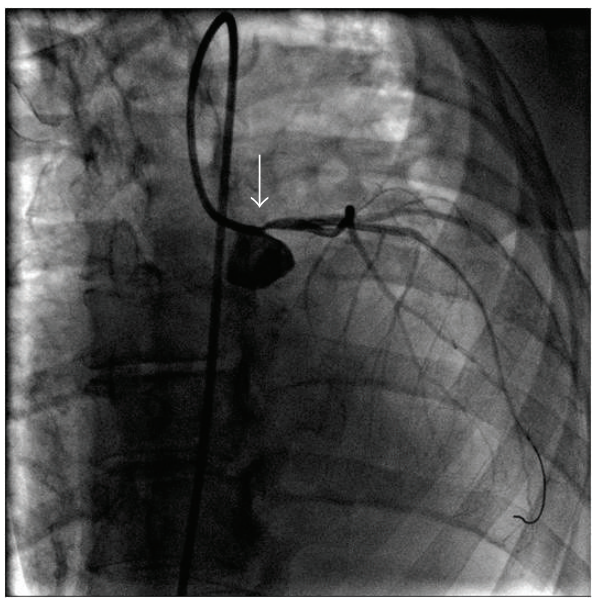

(a)

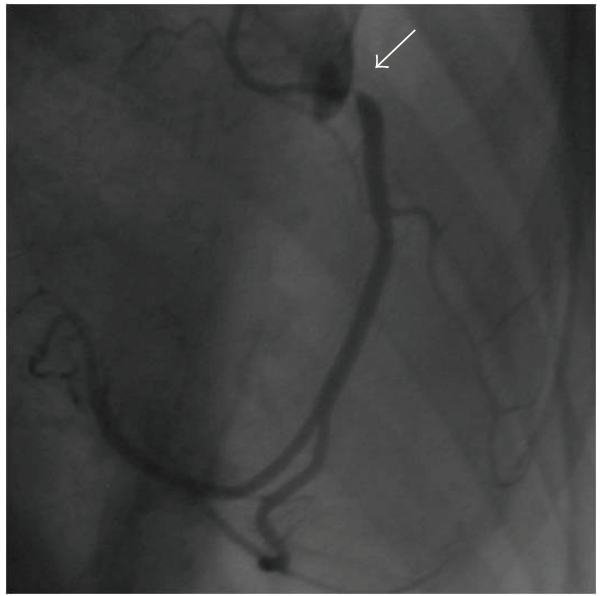

(c)

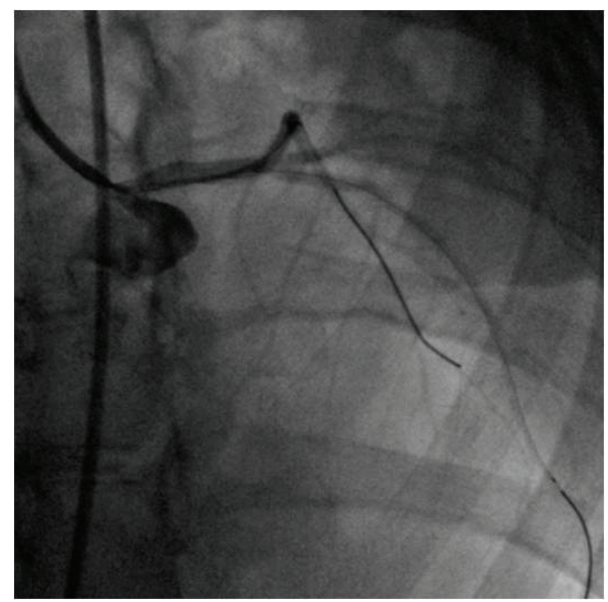

(b)

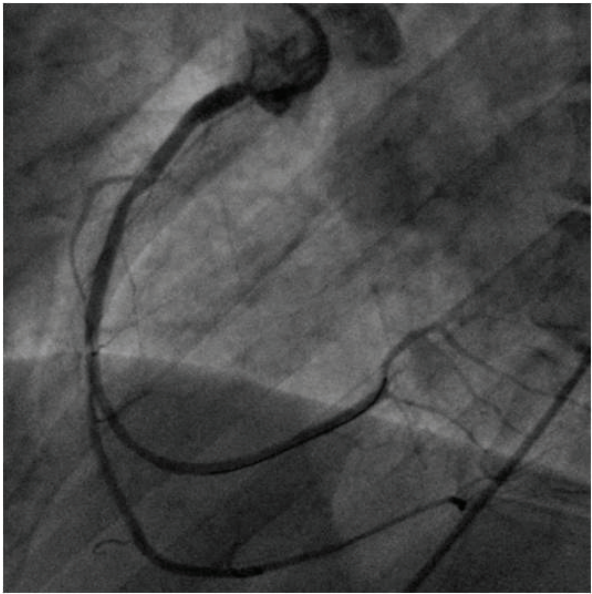

(d)

FIGURE 2: (a) Left coronary artery showing critical ostial left main stenosis (arrow). (b) Final result of the left main direct stenting with everolimus eluting stent. (c) Tight ostial lesion of the right coronary artery (RCA; arrow). (d) Final result after direct stenting of ostial RCA with sirolimus eluting stent. 


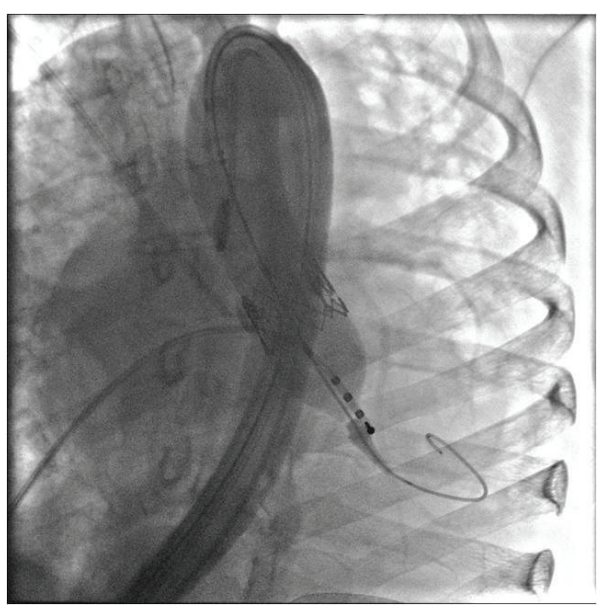

(a)

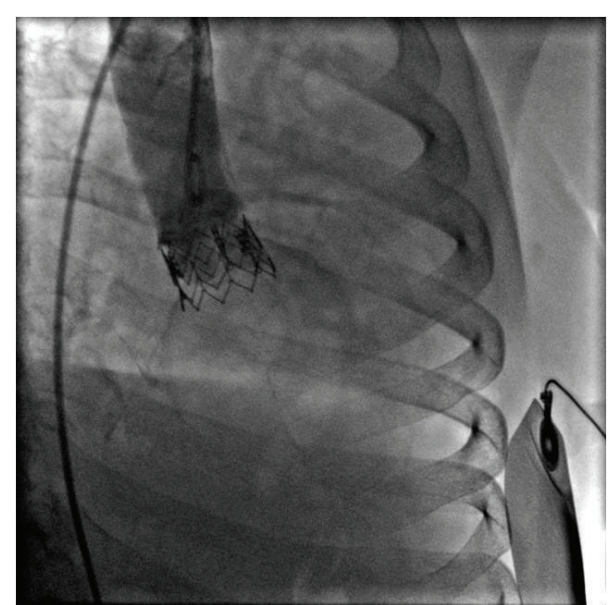

(b)

FIgURE 3: (a) Transcatheter aortic valve implantation (Edwards SAPIEN XT $23 \mathrm{~mm}$ ). (b) Aortography after TAVI procedure.

damping pressure) and critical ostial right coronary artery (RCA) disease (Figure 2). Severe, diffuse calcification of the ascending aorta was also present. The cardiac catheterization showed severe aortic valve stenosis (peak-to-peak gradient $70 \mathrm{mmHg}$ ) and pulmonary artery hypertension (mean pulmonary artery pressure $35 \mathrm{mmHg}$, capillary wedge pressure $20 \mathrm{mmHg}$ ).

Considering the high surgical risk due to severe restrictive lung disease, severe calcification of the ascending aorta, and postradiation thoracic adherence, the heart team planned a staged percutaneous approach. The patient underwent a successful coronary angioplasty with drug eluting stent implantation on ostial RCA and LM (sirolimus eluting stent $3.0 \times 13 \mathrm{~mm}$ on RCA, everolimus eluting stent $3,5 \times 12 \mathrm{~mm}$ on LM, Figure 2). According to angio-CT sizing, a $23 \mathrm{~mm}$ Edwards SAPIEN XT valve (Edwards Lifesciences, Irvine, CA) was selected for the procedure. One month later, she underwent TAVI procedure, performed through the right femoral artery (Figure 3).

After the procedure, the echocardiogram showed a markedly decreased transaortic valvular gradient (mean gradient $10 \mathrm{mmHg}$ ) with a mild periprosthetic regurgitation, improved left ventricular systolic function, and mild mitral regurgitation. The patient was discharged on aspirin, clopidogrel up to twelve months, ivabradine, and furosemide.

At 24 months' follow-up, she is in NYHA II functional class, fully carrying out normal daily activities. Echocardiogram confirms the good performance of the prosthetic valve and normal left ventricular systolic function.

\section{Discussion}

This case report describes a fully percutaneous treatment of the cardiovascular consequences of thoracic exposure to radiation therapy. This modern approach offered a concrete chance to this young woman, who otherwise should have undergone a very high risk surgical intervention.

The risk of long-term radiotherapy damage depends on the radiation dose and the field of exposure [8]. The pathogenesis of radiation-induced coronary artery disease (CAD) is complex and not yet fully understood; radiation exposure may act as an independent risk factor of arteriosclerosis. Radiation-induced valvular disease is uncommon [8]; valve lesions are diagnosed on average 11.5 years after radiation exposure and symptoms occur at least 5 years later [9].

The pathophysiology of radiation-induced valvular disease is not completely clarified: cellular injury, combined with pressure-related trauma, may cause valvular fibrosis and calcification [10, 11]: irradiation seems to trigger a degenerative process that lasts for years.

Most radiation effects are dose related and it is probable that modern techniques with lower radiation exposure and smaller treatment volumes may reduce these risks.

TAVI is a highly effective procedure for selected patients who are at high surgical risk. The lack of long-term outcomes limits the use of TAVI to the elderly. In this case, the young age represented a concern, overweighted by the prohibitive surgical risk.

\section{Conflict of Interests}

No conflict of interests relevant to this paper was reported by any of the authors.

\section{Acknowledgment}

The authors are grateful to Dr. Giorgio Fasolini, Radiologist at the Department of Diagnostic Imaging of Papa Giovanni XXIII Hospital, Bergamo, for his valuable contribution.

\section{References}

[1] F. Orzan, A. Brusca, M. R. Conte, P. Presbitero, and M. C. Figliomeni, "Severe coronary artery disease after radiation therapy of the chest and mediastinum: clinical presentation and treatment," British Heart Journal, vol. 69, no. 6, pp. 496-500, 1993.

[2] F. A. Stewart, I. Seemann, S. Hoving, and N. S. Russell, "Understanding radiation-induced cardiovascular damage and 
strategies for intervention," Clinical Oncology, vol. 25, no. 10, pp. 617-624, 2013.

[3] S. L. Galper, J. B. Yu, P. M. Mauch et al., "Clinically significant cardiac disease in patients with Hodgkin lymphoma treated with mediastinal irradiation," Blood, vol. 117, no. 2, pp. 412-418, 2011.

[4] R. A. Aqel and G. J. Zoghbi, "Radiation therapy-related cardiovascular disease," Journal of Heart and Lung Transplantation, vol. 25, no. 2, pp. 257-258, 2006.

[5] M. Thomas, G. Schymik, T. Walther et al., "Thirty-day results of the SAPIEN aortic bioprosthesis European outcome (SOURCE) registry: a European registry of transcatheter aortic valve implantation using the edwards SAPIEN valve," Circulation, vol. 122, no. 1, pp. 62-69, 2010.

[6] R. R. Makkar, G. P. Fontana, H. Jilaihawi et al., "Transcatheter aortic-valve replacement for inoperable severe aortic stenosis," The New England Journal of Medicine, vol. 366, pp. 1696-1704, 2012.

[7] S. R. Kapadia, E. M. Tuzcu, R. R. Makkar et al., "Long-term outcomes of inoperable patients with aortic stenosis randomly assigned to transcatheter aortic valve replacement or standard therapy," Circulation, vol. 130, pp. 1483-1492, 2014.

[8] M. C. Hull, C. G. Morris, C. J. Pepine, and N. P. Mendenhall, "Valvular dysfunction and carotid, subclavian, and coronary artery disease in survivors of Hodgkin lymphoma treated with radiation therapy," Journal of the American Medical Association, vol. 290, no. 21, pp. 2831-2837, 2003.

[9] R. G. Carlson, W. R. Mayfield, S. Normann, and J. A. Alexander, "Radiation-associated valvular disease," Chest, vol. 99, pp. 538$545,1991$.

[10] M. D. Brand, C. A. Abadi, G. P. Aurigemma, H. L. Dauerman, and T. E. Meyer, "Radiation-associated valvular heart disease in Hodgkin's disease is associated with characteristic thickening and fibrosis of the aortic-mitral curtain," Journal of Heart Valve Disease, vol. 10, no. 5, pp. 681-685, 2001.

[11] N. M. Katz, A. W. Hall, and M. D. Cerqueira, "Radiation induced valvulitis with late leaflet rupture," Heart, vol. 86, no. 6, article e20, 2001. 


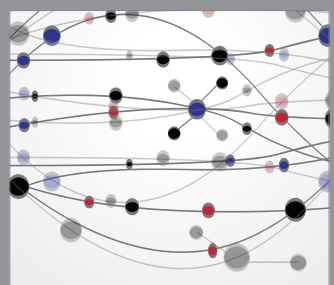

The Scientific World Journal
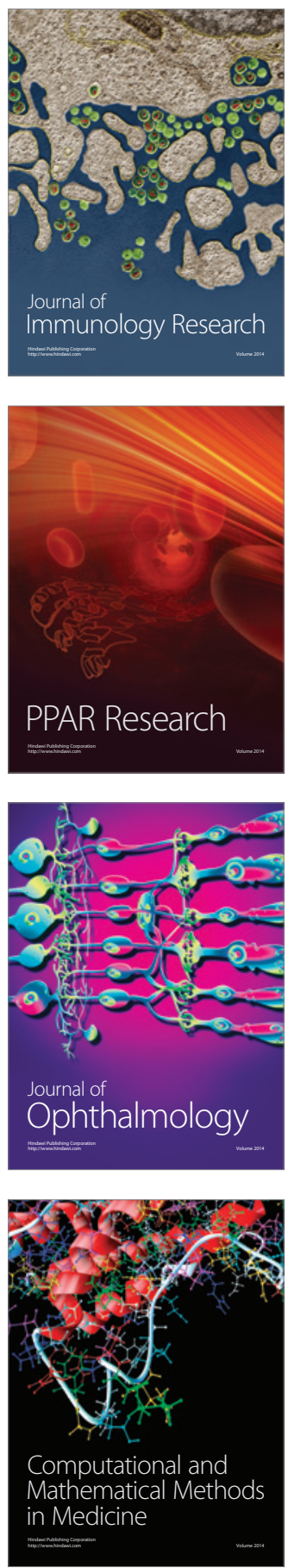

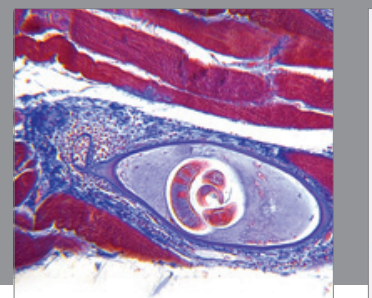

Gastroenterology

Research and Practice
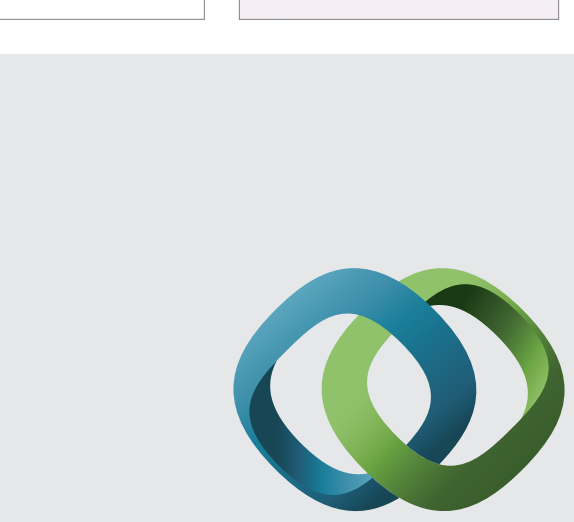

\section{Hindawi}

Submit your manuscripts at

http://www.hindawi.com
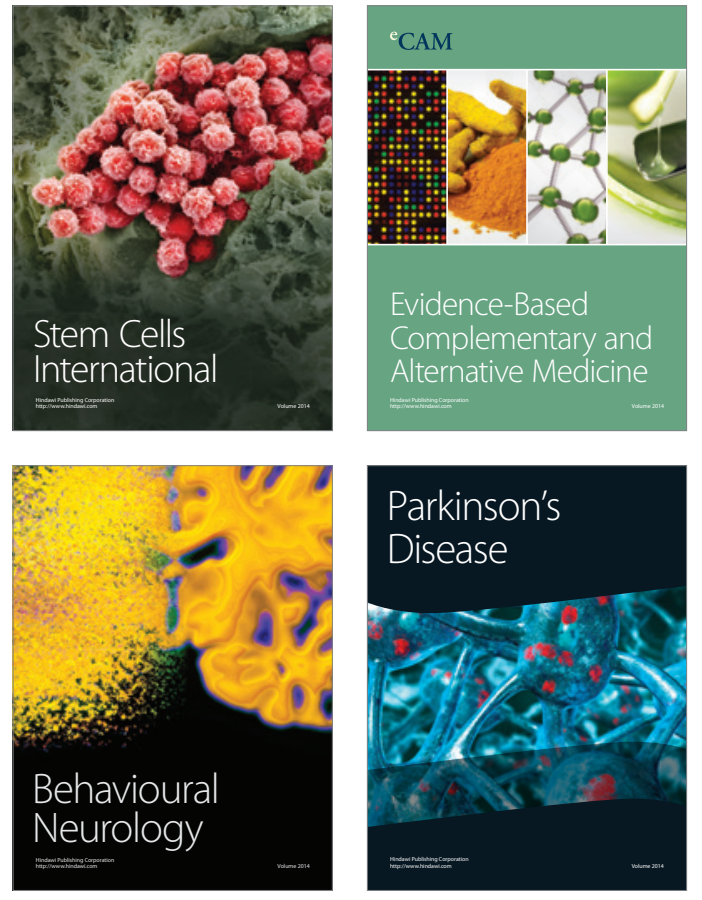
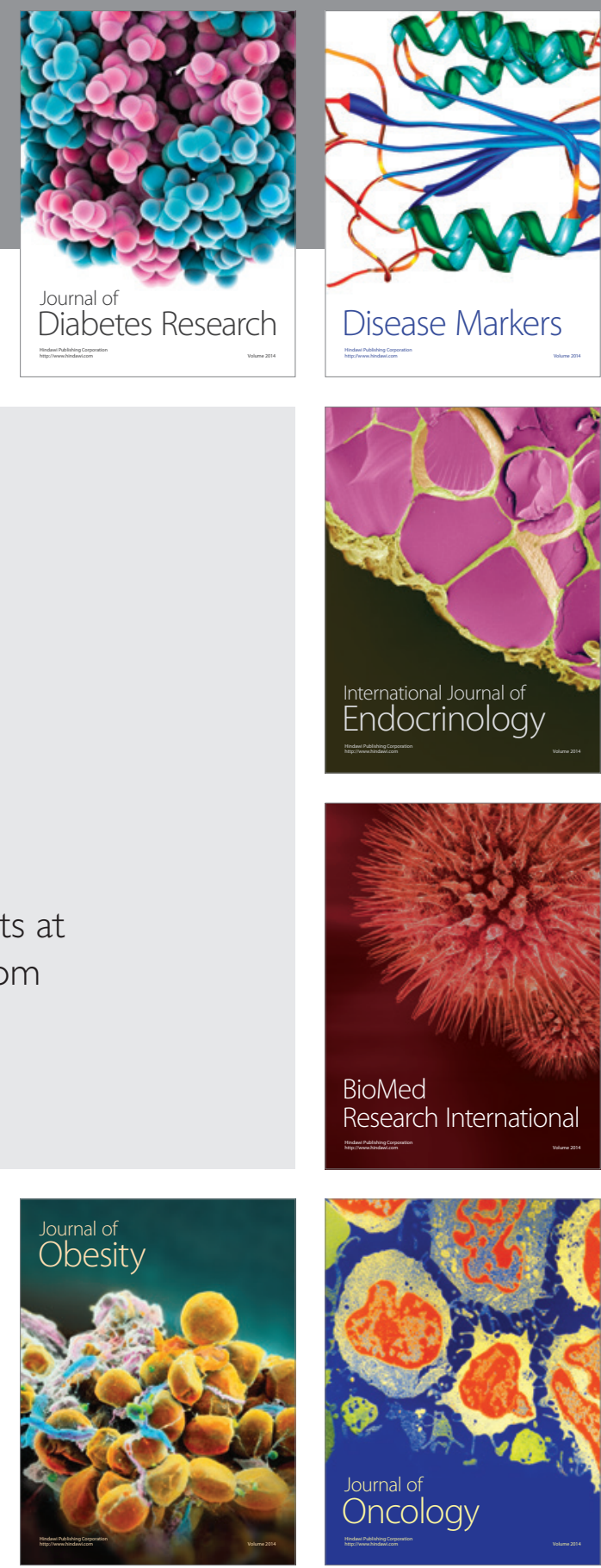

Disease Markers
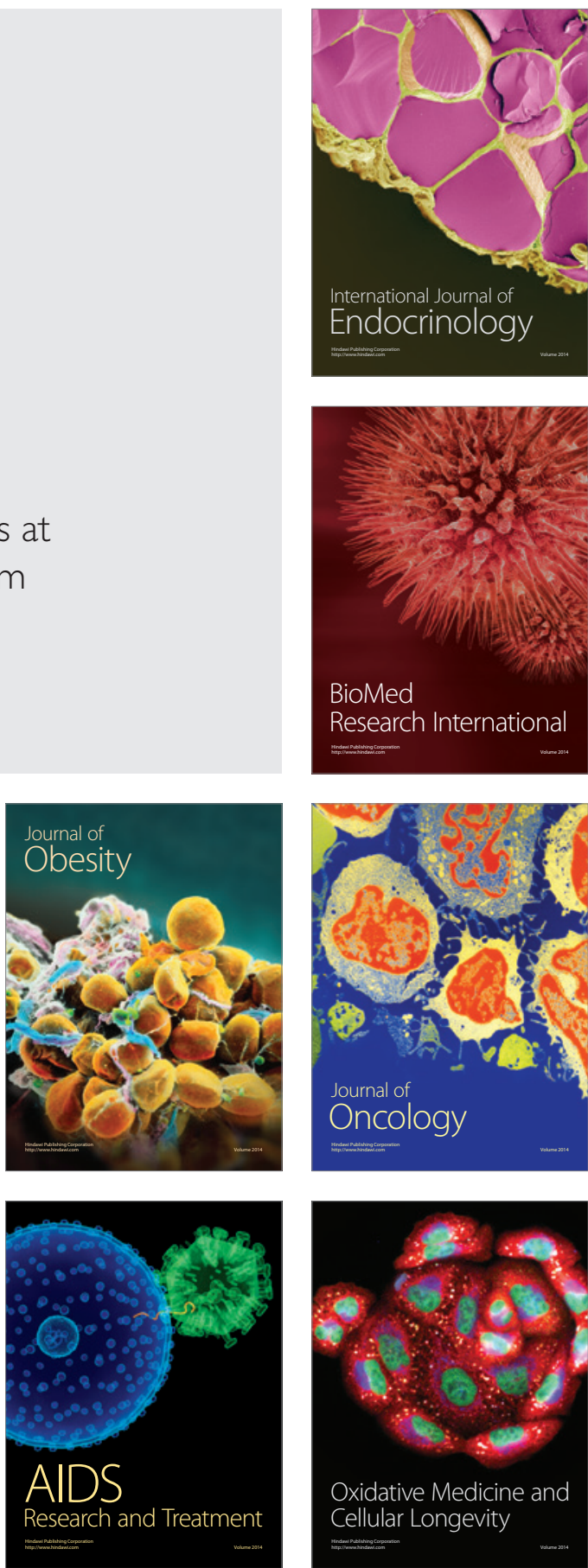